\title{
REVIEW
}

\section{Clinical review: Respiratory monitoring in the ICU - a consensus of 16}

\author{
Laurent Brochard', Greg S Martin², Lluis Blanch³, Paolo Pelosi ${ }^{4}$, F Javier Belda5, Amal Jubran', Luciano Gattinoni?, \\ Jordi Mancebo ${ }^{8}$, V Marco Ranieri', Jean-Christophe M Richard', Diederik Gommers ${ }^{10}$, Antoine Vieillard-Baron"1, \\ Antonio Pesenti12, Samir Jaber ${ }^{13}$, Ola Stenqvist ${ }^{14}$ and Jean-Louis Vincent*15
}

\begin{abstract}
Monitoring plays an important role in the current management of patients with acute respiratory failure but sometimes lacks definition regarding which 'signals' and 'derived variables' should be prioritized as well as specifics related to timing (continuous versus intermittent) and modality (static versus dynamic). Many new techniques of respiratory monitoring have been made available for clinical use recently, but their place is not always well defined. Appropriate use of available monitoring techniques and correct interpretation of the data provided can help improve our understanding of the disease processes involved and the effects of clinical interventions. In this consensus paper, we provide an overview of the important parameters that can and should be monitored in the critically ill patient with respiratory failure and discuss how the data provided can impact on clinical management.
\end{abstract}

\section{Introduction}

Monitoring plays an important role in the current management of patients with acute respiratory failure. However, unlike monitoring of other organs and functions, monitoring of respiratory function in the critically ill sometimes lacks definition regarding which 'signals' and 'derived variables' should be prioritized as well as specifics related to timing (continuous versus intermittent) and modality (static versus dynamic). In this consensus paper, we summarize current modes of respiratory monitoring and their potential practical applications (Table 1).

\footnotetext{
*Correspondence: jlvincen@ulb.ac.be

${ }^{15}$ Department of Intensive Care, Erasme Hospital, Université Libre de Bruxelles, 808 route de Lennik, 1070 Brussels, Belgium

Full list of author information is available at the end of the article
}

The amount of text devoted to each modality varies according to perceived familiarity with the technique: more text is dedicated to novel strategies and those with newer indications.

\section{Monitoring systems \\ 1. Gas exchange \\ Pulse oximetry and transcutaneous carbon dioxide monitoring}

Pulse oximetry is widely used in anesthesiology and intensive care and, in intensive care unit (ICU) patients, has a bias of less than $1 \%$ and a good to moderate precision [1]; accuracy decreases in hypoxemia (oxygen saturation as measured by pulse oximetry, or $\mathrm{SpO}_{2}$, of less than $90 \%$ ). Among the intrinsic limitations of pulse oximetry are that it is insensitive to changes in arterial partial pressure of oxygen $\left(\mathrm{PaO}_{2}\right)$ at high $\mathrm{PaO}_{2}$ levels and cannot distinguish between normal hemoglobin and methemoglobin or carboxyhemoglobin. Nail polish may affect the measurement by about $2 \%$ (not really clinically relevant) [2], and pulse oximetry can slightly underestimate arterial oxygen saturation $\left(\mathrm{SaO}_{2}\right)$ in patients with darkly pigmented skin [3]. Altered skin perfusion and carboxyhemoglobin can also lead to inaccurate pulse oximetry readings. The type of probe can make a difference, and accuracy is usually better for finger than for earlobe probes [4]. False alarms are common, usually because of motion artifacts, particularly in the pediatric population.

Pulse oximetry readings should be used to provide an early warning sign, decreasing the need for blood gas measurements. In a randomized controlled trial in more than 20,000 surgical patients [5], pulse oximetry was not associated with decreased postoperative complications or mortality, but $80 \%$ of the anesthesiologists felt more secure when a pulse oximeter was used!

Transcutaneous partial pressure of carbon dioxide $\left(\mathrm{PCO}_{2}\right)$ monitors have also been developed with probes generally placed on the earlobe. Precision of transcutaneous $\mathrm{PCO}_{2}$ measurements has improved as technology has advanced, and devices have become smaller but still need 
Table 1. Summary of the different monitoring techniques

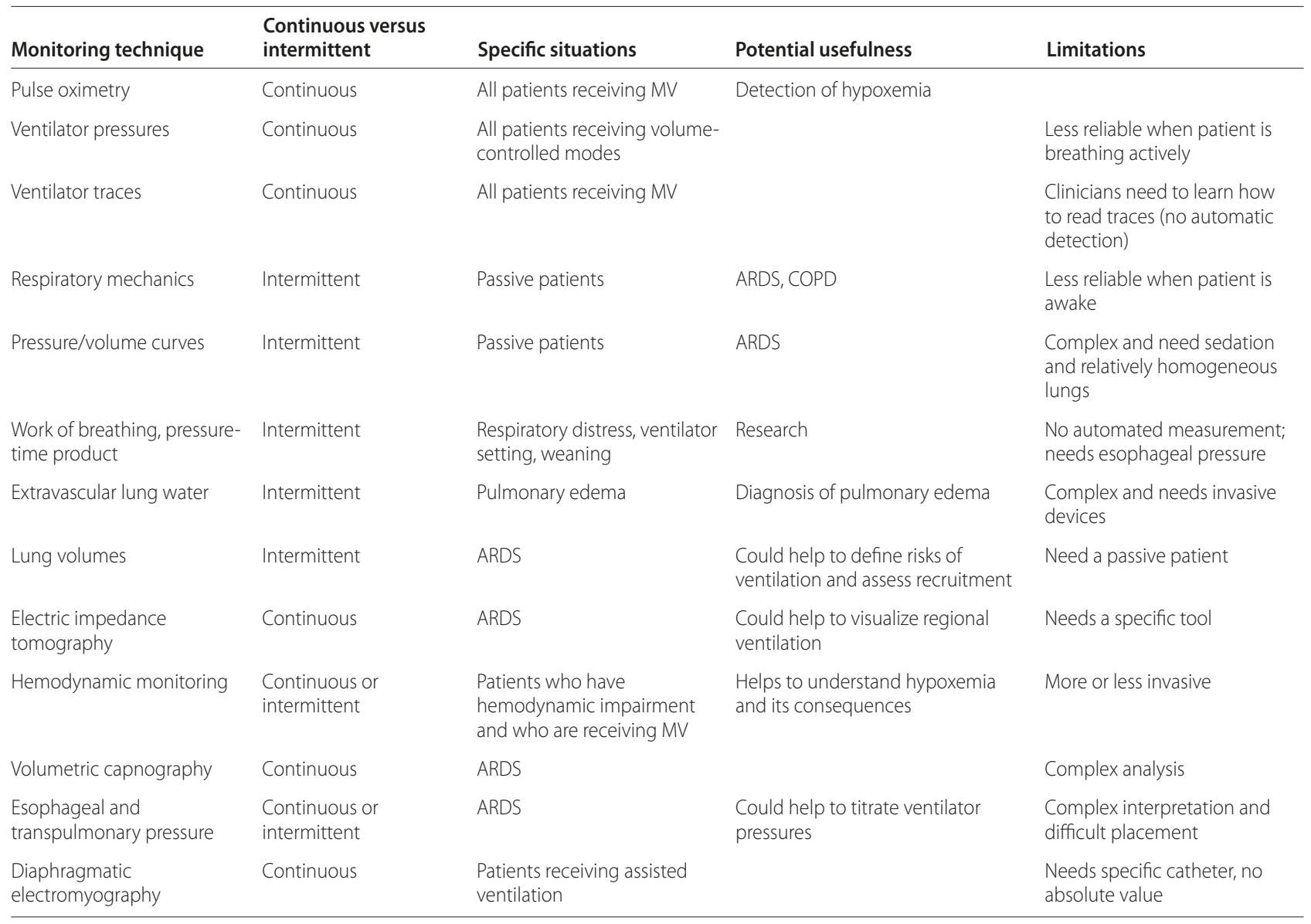

ARDS, acute respiratory distress syndrome; COPD, chronic obstructive pulmonary disease; MV, mechanical ventilation.

regular recalibration [6]. Their place in the respiratory monitoring of ICU patients has not yet been defined.

\section{Volumetric capnography and dead space calculation}

The expiratory capnogram provides qualitative information on the waveform patterns associated with mechanical ventilation and quantitative estimation of expired $\mathrm{CO}_{2}$. Capnography tracings show three phases (Figure 1) [7]: phase I contains gas from the apparatus and anatomic dead space (airway), phase II represents increasing $\mathrm{CO}_{2}$ concentration resulting from progressive emptying of alveoli, and phase III represents alveolar gas. Phase III is often referred to as the plateau and its appearance is relatively flat or has a small positive slope; the highest point is the end-tidal $\mathrm{PCO}_{2}\left(\mathrm{PetCO}_{2}\right)$. The almost rectangular shape of the expired capnogram depends on the homogeneity of the gas distribution and alveolar ventilation. Lung heterogeneity creates regional differences in $\mathrm{CO}_{2}$ concentration, and gas from high $\mathrm{V} / \mathrm{Q}$ regions first appears in the upper airway during exhalation. This sequential emptying contributes to the rise of the alveolar plateau; the greater the V/Q heterogeneity, the steeper the expired $\mathrm{CO}_{2}$ slope. Accordingly, the slope of the alveolar plateau has been shown to correlate with the severity of airflow obstruction [8].

Physiologic dead space $\left(\mathrm{Vd}_{\text {phys }}\right)$ can be easily calculated from the Enghoff modification of the Bohr equation by using arterial partial pressure of carbon dioxide $\left(\mathrm{PaCO}_{2}\right)$ with the assumption that $\mathrm{PaCO}_{2}$ is similar to alveolar $\mathrm{PCO}_{2}$ :

$$
\mathrm{Vd}_{\text {phys }} / \mathrm{V}_{\mathrm{T}}=\left(\mathrm{PaCO}_{2}-\mathrm{P}_{\mathrm{E}} \mathrm{CO}_{2}\right) / \mathrm{PaCO}_{2} \text {, }
$$

where $\mathrm{V}_{\mathrm{T}}$ is the tidal volume and $\mathrm{P}_{\mathrm{E}} \mathrm{CO}_{2}$ is the partial pressure of $\mathrm{CO}_{2}$ in mixed expired gas and is equal to the mean expired $\mathrm{CO}_{2}$ fraction multiplied by the difference between the atmospheric pressure and the water vapor pressure. $\mathrm{Vd}_{\text {phys }}$ is increased in acute respiratory distress syndrome (ARDS), and a high dead space fraction represents an impaired ability to excrete $\mathrm{CO}_{2}$ because of any kind of V/Q mismatch. Several authors $[9,10]$ have demonstrated that increased $\mathrm{Vd}_{\text {phys }}$ values are independently associated with an increased risk of death in these patients. 


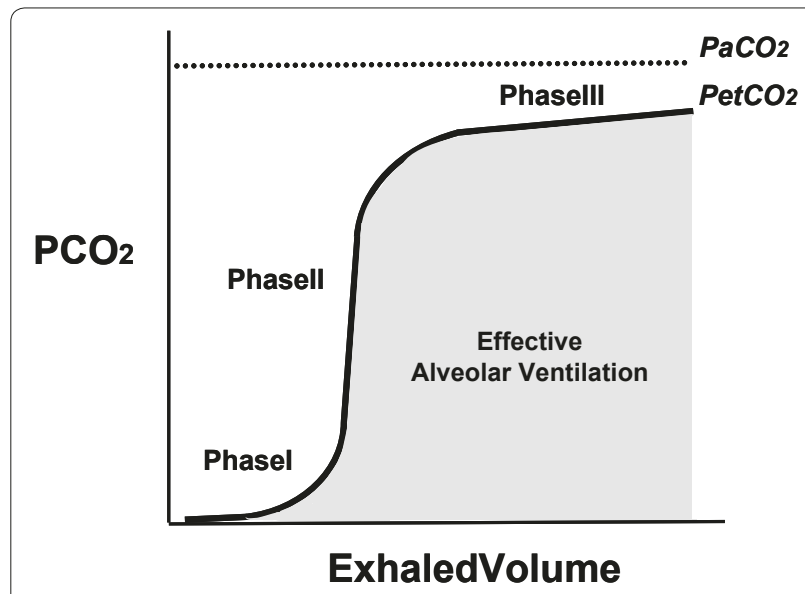

Figure 1. The three phases of capnography tracings. Phase I contains gas from the apparatus and anatomic dead space (airway), phase II represents increasing carbon dioxide concentration resulting from progressive emptying of alveoli, and phase III represents alveolar gas. The highest point of phase III is the end-tidal partial pressure of carbon dioxide $\left(\mathrm{PetCO}_{2}\right)$. $\mathrm{PaCO}_{2}$, arterial partial pressure of carbon dioxide; $\mathrm{PCO}_{2}$, partial pressure of carbon dioxide.

Since $\mathrm{Vd}_{\text {phys }} / \mathrm{V}_{\mathrm{T}}$ measures the fraction of each tidal breath that is wasted on alveolar dead space $\left(\mathrm{Vd}_{\mathrm{alv}}\right)$ and airway dead space $\left(\mathrm{Vd}_{\mathrm{aw}}\right)$, the $\mathrm{Vd}_{\mathrm{aw}}$ must be subtracted from $\mathrm{Vd}_{\text {phys }} / \mathrm{V}_{\mathrm{T}}$ to obtain the $\mathrm{Vd}_{\text {alv }} / \mathrm{V}_{\mathrm{T}}$ [11]. By using the PetCO $\mathrm{C}_{2}$ instead of $\mathrm{P}_{\mathrm{E}} \mathrm{CO}_{2}$ in the equation, the $\mathrm{Vd}_{\text {alv }}$ can be calculated. Equating the alveolar $\mathrm{PCO}_{2}$ to the arterial $\mathrm{PaCO}_{2}$ is, however, valid only in healthy subjects. In patients with high right-to-left shunt, $\mathrm{PaCO}_{2}$ is higher than alveolar $\mathrm{PCO}_{2}$ because of the shunted blood with high $\mathrm{PvCO}_{2}$ (partial pressure of carbon dioxide in mixed venous blood). Without correction [12], it must be remembered that a high dead space also includes the shunt effect.

$\mathrm{PaCO}_{2}$ can be grossly estimated by $\mathrm{PetCO}_{2}$. Monitoring PetCO ${ }_{2}$ can also help to track $\mathrm{PaCO}_{2}$ when changes in $\mathrm{PaCO}_{2}$ are to be avoided (especially in critically ill, neurological patients with normal lungs). The gradient between $\mathrm{PaCO}_{2}$ and $\mathrm{PetCO}_{2}$ widens in ARDS and correlates across the different levels of $\mathrm{Vd}_{\text {phys }}$ [13]. The difference between $\mathrm{PaCO}_{2}$ and $\mathrm{PetCO}_{2}$ is reduced by using the maximal values of $\mathrm{PetCO}_{2}$ over time [14].

In patients with sudden pulmonary vascular occlusion due to pulmonary embolism, the resultant V/Q mismatch produces an increase in $\mathrm{Vd}_{\mathrm{alv}}$. When volumetric capnography is used as a bedside technique, the association of a normal $\mathrm{D}$-dimer assay result plus a normal $\mathrm{Vd}_{\mathrm{alv}}$ is a highly sensitive screening test to rule out the diagnosis of pulmonary embolism [15]. Volumetric capnography has also been shown to be an excellent tool for monitoring thrombolytic efficacy in patients with pulmonary embolism [16].
When the application of positive end-expiratory pressure (PEEP) results in global lung recruitment, physiologic and alveolar dead space decrease [17]; the reverse is true when PEEP application results in lung overdistension [18]. Therefore, volumetric capnography may also be helpful to identify overdistension or better alveolar gas diffusion [19].

In summary, volumetric capnography has important potential for monitoring the difficult-to-ventilate patient. Volumetric capnography needs sophisticated equipment and this has limited its widespread use.

\section{Blood gases}

The $\mathrm{PaO}_{2} /$ inspired fraction of oxygen $\left(\mathrm{PaO}_{2} / \mathrm{FiO}_{2}\right)$ ratio is still the most frequently used variable for evaluating the severity of lung failure and is included in the current definition of acute lung injury/ARDS [20]. The $\mathrm{PaO}_{2} / \mathrm{FiO}_{2}$ ratio is often a curvilinear (U-shaped) relationship, being at its lowest for moderate ranges of $\mathrm{FiO}_{2}$, depending on the shunt level, the hemoglobin value, and the arteriovenous difference in $\mathrm{O}_{2}$ content [21-23]. For a given $\mathrm{PaO}_{2} / \mathrm{FiO}_{2}$ ratio, the higher the $\mathrm{FiO}_{2}$, the poorer the prognosis [24]. In patients with ARDS, the $\mathrm{PaO}_{2} / \mathrm{FiO}_{2}$ ratio is dependent on the PEEP level and can be a surrogate, though imperfect, marker of recruitment [25]. Hemodynamic status (via the mixed venous oxygen tension, or $\mathrm{PvO}_{2}$ ) and intracardiac shunt (patent foramen ovale) also influence the $\mathrm{PaO}_{2} / \mathrm{FiO}_{2}$ ratio [26]. Despite its limitations, this ratio remains the most commonly used means of assessing severity of lung disease. The oxygen index ([mean airway pressure $\left.\times \mathrm{FiO}_{2} \times 100\right] / \mathrm{PaO}_{2}$ ) accounts better for the influence of ventilator pressures on oxygenation value [27].

$\mathrm{PaCO}_{2}$-related variables are tightly correlated to outcome [28] and to lung structural changes [29] sometimes better than oxygen-related variables (such as shunt fraction) [30,31].

\section{Extravascular lung water}

Extravascular lung water (EVLW) is a quantitative measure of pulmonary edema and is correlated, in multiple patient populations, to mortality [32]. Normal values are 5 to $7 \mathrm{~mL} / \mathrm{kg}$ (indexed to predicted body weight), and quantities above $10 \mathrm{~mL} / \mathrm{kg}$ are associated with adverse clinical outcomes [33].

Indicator dilution techniques for measuring EVLW are available for bedside use in critically ill patients. The single-indicator technique is now well validated and offers the additional value of simultaneously measuring cardiovascular performance (cardiac output, fluid responsiveness, and filling volumes). Current technology uses an injection of cold saline into the right atrium and assesses transpulmonary thermodilution in the arterial system by using a femoral or brachial catheter. 
Limitations of the technique include requirements for good indicator mixing without loss and for constant blood flow and temperature. EVLW can be assessed only in perfused areas of the lung [34].

EVLW measurements may be used in combination with other cardiovascular and pulmonary parameters to diagnose pulmonary edema. Complementary information from indicator dilution techniques, such as cardiac filling volumes, helps to differentiate between hydrostatic/cardiogenic pulmonary edema and permeability edema [35]. Although repeated measures could be used to assess response to interventions [35], it is unclear how fast the response time is and whether this technique can be used as a tool to guide therapy.

\section{Respiratory mechanics Compliance and resistance}

Monitoring airway pressures can provide important information. In flow (volume)-controlled mode, peak airway pressure is determined by both resistance and compliance - a high peak pressure with a much lower plateau pressure indicates a high resistance related either to the patient (bronchospasm) or to the equipment (small-diameter endotracheal tube [ETT] or narrow or obstructed tubing). Plateau pressure measurement requires a pause at end-insufflation of at least 200 to $500 \mathrm{~ms}$ with a quasi-steady pressure. Longer pauses may be required to precisely estimate lung homogeneities or pendelluft phenomena but their clinical role is unclear. Patients must be relaxed during this measurement.

Compliance is easily calculated as the ratio between $\mathrm{V}_{\mathrm{T}}$ and plateau pressure minus PEEP (Figure 2). Elastance is the reverse of compliance (how much pressure we need for a given volume). A low compliance-high elastance reflects mainly a small aerated lung available for ventilation. High plateau pressure may be related to either low compliance or high end-expiratory pressure (flow limitation or dynamic hyperinflation). Peak airway pressure is very sensitive to changes in respiratory mechanics; performing end-inspiratory and end-expiratory pauses may allow the exact cause of a high peak airway pressure to be determined. Compliance is not easily assessed on pressure-predetermined modes, especially when the expiratory phase starts before flow stops. In such cases, an end-inspiratory occlusion test should be performed to assess plateau pressure, even in time-cycled pressurelimited modes.

Measurements of respiratory mechanics are simple to perform and provide useful and relevant information for severity assessment and ventilator management. They are really reliable only in passive conditions of ventilation, in which plateau pressure monitoring is essential for adequate ventilatory management.

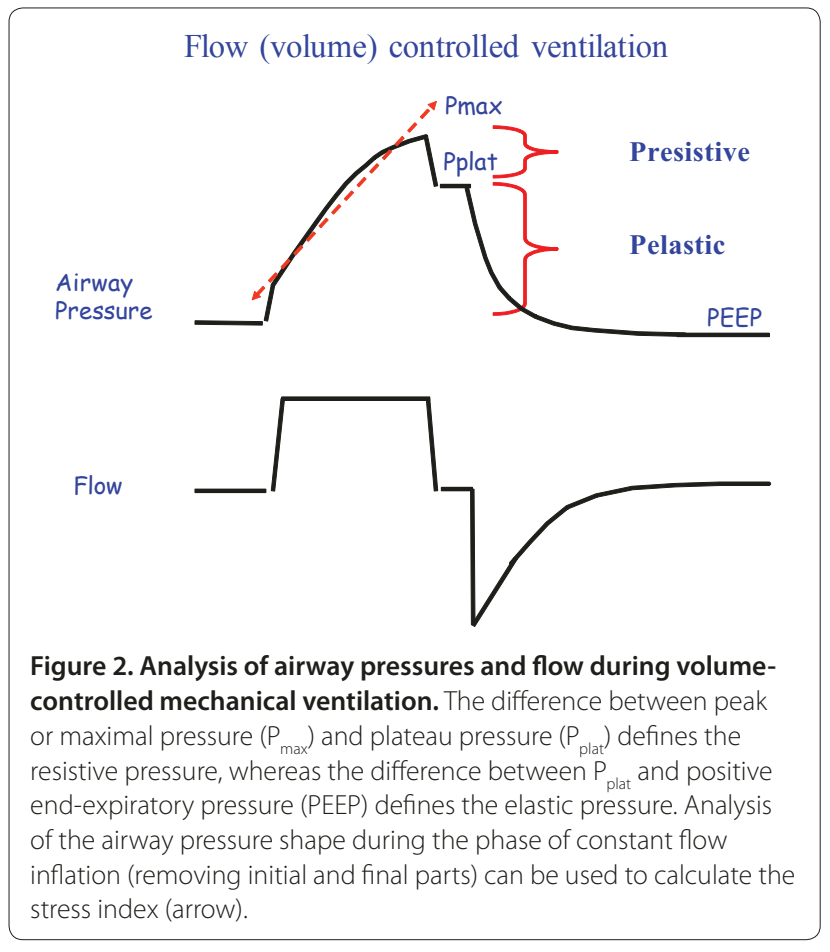

Pressure/volume curves

The study of lung mechanics is particularly helpful in patients with ARDS. Study of pressure/volume (P/V) curves requires insufflations at very low flow to avoid the influence of the resistive components [36-38]. The accent has often been placed on identification of the lower (LIP) [39] and upper (UIP) [40] inflection points on the P/V curve, but this approach has limitations. First, identifying the LIP or UIP is sometimes difficult. Second, recruitment takes place throughout the P/V curve $[41,42]$, and recruitment and overdistension can occur at the same time. Third, application of an optimal PEEP level should, ideally, be assessed from the expiratory rather than the inspiratory limb of this relationship.

Interpretation of $\mathrm{P} / \mathrm{V}$ curves is difficult in the presence of altered chest compliance [43]. Chest wall compliance may be decreased in cases of increased abdominal pressure, thoracic trauma, large pleural effusions, obesity, and so on. Measuring esophageal pressure (surrogate of pleural pressure) allows pressure dissipated through the chest wall to be differentiated from pressure distending the lungs (transpulmonary pressure). In medical patients, the chest wall has little to modest impact on respiratory pressures [43]; whether this is different in patients with abdominal surgery or obesity needs further study. Nevertheless, the concept remains that ventilating down to too low a pressure may result in so-called atelectrauma (opening and closing the alveoli repeatedly), and inflating the lungs too much when most of the recruitment has already occurred may result in overdistension. 
The difference between the inspiratory and expiratory parts of the $\mathrm{P} / \mathrm{V}$ curve are related, in part, to hysteresis [44], which reflects whether PEEP should be increased or not. If the two limbs of the curve are superimposed, increasing PEEP will not help; if there is a large difference in volume between inspiratory and expiratory portions, PEEP may help (Figure 3). Quantification of recruitment requires multiple $\mathrm{P} / \mathrm{V}$ curves [45], and, although $\mathrm{P} / \mathrm{V}$ curves are now more frequently available on commercial ventilators, the lack of an estimate of recruitment still limits clinical usefulness. The $\mathrm{P} / \mathrm{V}$ curve technique has thus been used mainly as a research tool.

During constant flow insufflations, a stress index (Figure 2) can be calculated from the shape of the airway pressure-versus-time curve (which is essentially the opposite of the P/V curve since during constant flow time equals volume) [46]. If there is downward concavity, compliance improves over time (stress index of less than 1), reflecting tidal recruitment of collapsed alveoli; if the curve is straight (stress index of 1), compliance is constant, reflecting ventilation of the normal lung; and if there is upward concavity (stress index of greater than 1), it means that compliance is decreasing over time during insufflations, reflecting overinflation. A stress index of less than 1 may suggest a need to increase PEEP; a stress index of greater than 1 may suggest a need to reduce $\mathrm{V}_{\mathrm{T}}$ [47]. The same limitations described for the $\mathrm{P} / \mathrm{V}$ curve (that is, recruitment and overdistension) apply to this kind of analysis. The clinical place and reliability of the stress index are still debated [48].

\section{Diaphragmatic function}

Mechanical ventilation has been associated with ventilator-induced diaphragmatic dysfunction [49]. Diaphragmatic function can be altered early and is related to the duration of mechanical ventilation [50]. The transdiaphragmatic pressure difference (gastric minus esophageal pressure) reflects diaphragmatic function but only in patients who have spontaneous ventilatory breaths and who can cooperate. Magnetic phrenic stimulation can be used to assess diaphragmatic function [51] as a noninvasive method in sedated and non-sedated patients but remains a test of respiratory muscle function rather than a monitoring tool and is used mainly in research.

Measurements of diaphragmatic electrical activity are now possible and have been used to drive the ventilator during neurally adjusted ventilatory assist [52]. Although it does not provide absolute values, monitoring diaphragmatic electrical activity may be of potential interest to detect patient-ventilator asynchrony.

\section{Pressure and flow monitoring to assess asynchrony}

A considerable amount of information can be obtained from pressure and flow time curve analysis [53]. The

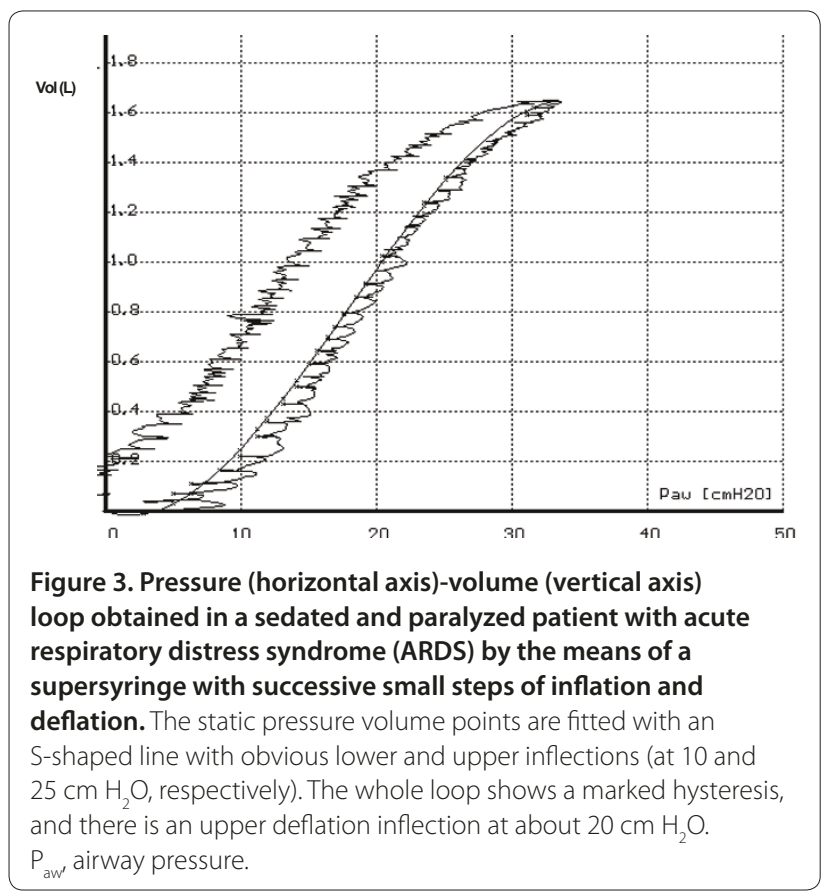

airflow trace can reveal the presence of auto-PEEP, when flow does not return to zero at the end of expiration (Figure 4). Dyssynchrony can be caused by poor or delayed ventilator triggering or cycling or both. Excessive levels of pressure support may result in ineffective triggering because they are associated with long inspiratory times and intrinsic PEEP [54], and insufficient assistance (for example, because of a short inspiratory time during assist/control ventilation) can also result in dyssynchrony. Auto-cycling, which results in excessive assistance and can be due to excessive triggering sensitivity or leaks, is difficult to detect. It may be revealed by reducing trigger sensitivity during a short series of 'test' breaths. Decreasing levels of pressure support and increasing expiratory trigger are the most effective solutions for ineffective efforts, whereas applying some PEEP may help but does not always work [55].

Recognizing dyssynchrony is important because it can indicate dynamic hyperinflation and may lead to excessive ventilatory assistance [55] and induce delays in weaning from mechanical ventilation [56] and severe sleep disruption [57]. There is no automatic method to detect dyssynchrony. Because of the clinical importance of dyssynchrony, one must learn how to recognize it from traces on the ventilator (this can be relatively easy, at least for gross asynchronies) [56] (Figure 5), and improved bedside training of curve reading is needed. Electromyography can also be of use in determining the presence of dyssynchrony but is rather complex for clinical use [58]. 


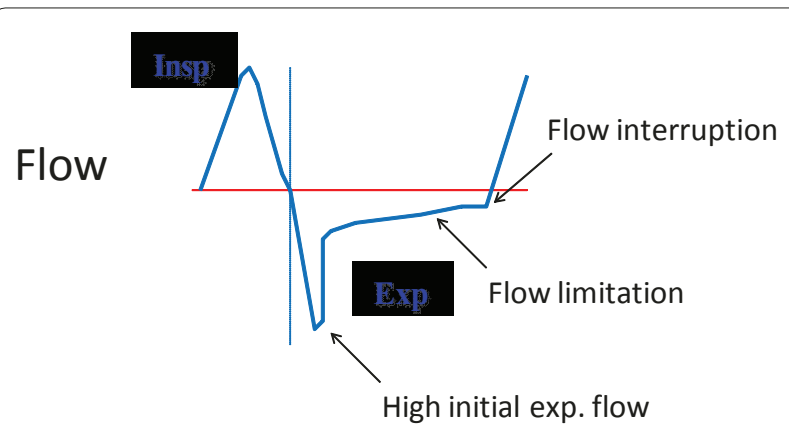

Figure 4. Example of a flow wave shape typical of expiratory flow limitation and intrinsic positive end-expiratory pressure (PEEP). Qualitative analysis of the expiratory part of the curve provides this information. Exp, expiration; Insp, inspiration.

\section{Work of breathing}

Work of breathing (WOB) represents the integral of the product of volume and pressure. It represents the energy associated with a given $\mathrm{V}_{\mathrm{T}}$ at a given pressure (spontaneous, mechanical, or both) [59]. The airway pressure is the pressure of the whole respiratory system (lungs plus chest wall); the transpulmonary pressure is the pressure needed to distend the lung parenchyma (airway pressure minus the pleural pressure); finally, the pleural pressure is the pressure needed to distend the chest wall. In the clinical/physiological setting, esophageal pressure is used as a surrogate for pleural pressure. 'Work' is not the same as 'effort' - effort without volume generation will not result in increased WOB. Normal WOB values range between 0.2 and $1 \mathrm{~J} / \mathrm{L}$.

In paralyzed patients with mechanical ventilation, plots of airway pressure versus $\mathrm{V}_{\mathrm{T}}$ indicate the total amount of work needed to inflate the respiratory system (that is, the work done by the ventilator on the whole respiratory system and the ETT). This is not the amount of work performed by the respiratory muscles, for which esophageal (pleural) pressure measurements are needed. One also needs to know the slope of the passive $\mathrm{P} / \mathrm{V}$ curve of the chest wall (which denotes the relaxation of the respiratory muscles). The surface encompassed within the passive $\mathrm{P} / \mathrm{V}$ curve of the chest wall and the negative esophageal pressure swing during an inspiratory effort is shown in the so-called Campbell diagram $[60,61]$. Finally, the two components of work (that is, elastic and resistive) can be split by joining the zero flow points at the beginning and the end of inspiration (Figure 6). The Campbell diagram allows the true work performed by the respiratory muscles to be estimated under different clinical conditions, even when auto-PEEP is present $[60,61]$.

Calculation of WOB may also be useful in understanding weaning failure. Jubran and colleagues [62] showed that the esophageal pressure trend during a spontaneous breathing trial (SBT) complemented the prediction of weaning outcome provided by the frequency/ $\mathrm{V}_{\mathrm{T}}$ index measured during the first minute of an SBT. Monitoring WOB can also theoretically help in titrating ventilator support. It could also be used to evaluate the effects of different ventilatory modes, understand the mechanisms of disease (weaning failure, acute asthma, and exacerbations of chronic obstructive pulmonary disease (COPD)), and evaluate the effects of therapeutic interventions (for example, bronchodilators [63]) and the influence of ventilator performance (triggering, flow delivery, and so on). Because it requires esophageal pressure measurement, this technique has been reserved largely for clinical research. It has potential for clinical use but few monitors provide bedside calculations.

\section{Occlusion pressure $\left(P_{0.1}\right)$}

The occlusion pressure, also referred to as $\mathrm{P}_{0.1}$, reflects the respiratory drive to breathe and is correlated to $\mathrm{WOB}$ for a given patient. Measurements of $\mathrm{P}_{0.1}$, now automatically provided on ventilators, may be useful to assess the patient's response to titration of ventilator settings (that is, flow rate, PEEP, and so on) and could be used as a surrogate of WOB to help titrate pressure support or external PEEP in cases of intrinsic PEEP [60,64]. A $\mathrm{P}_{0.1}$ of less than $2 \mathrm{~cm} \mathrm{H}_{2} \mathrm{O}$ is considered normal. This measure has been restricted largely to research. However, because the $\mathrm{P}_{0.1}$ is now more widely available in the ICU and is an extremely simple and rapid way to estimate central respiratory drive, its potential clinical role needs to be evaluated.

\section{Pressure-time product}

The pressure-time product is the integral of the pressure performed by the respiratory muscles during inspiration or expiration and time or both. The pressure-time product is an alternative to $\mathrm{WOB}$ and has some theoretical and practical advantages over WOB calculations. The pressure-time product is associated with oxygen consumption by the respiratory muscles [65] and could be considered a surrogate to quantify the metabolic expense of respiratory effort. Since it is independent from the ability of the patient to generate volume, the pressuretime product is relevant in situations in which there is a disconnection between effort and volume (for example, during asynchrony) [66]. Normal values for the pressuretime product range between 60 and $150 \mathrm{~cm} \mathrm{H}_{2} \mathrm{O} /$ second per minute [67].

\section{Transpulmonary and esophageal pressure}

Transpulmonary pressure is the difference in pressure between the inside (alveoli) and the outside (pleural space) of the lung. Variations in transpulmonary pressure 


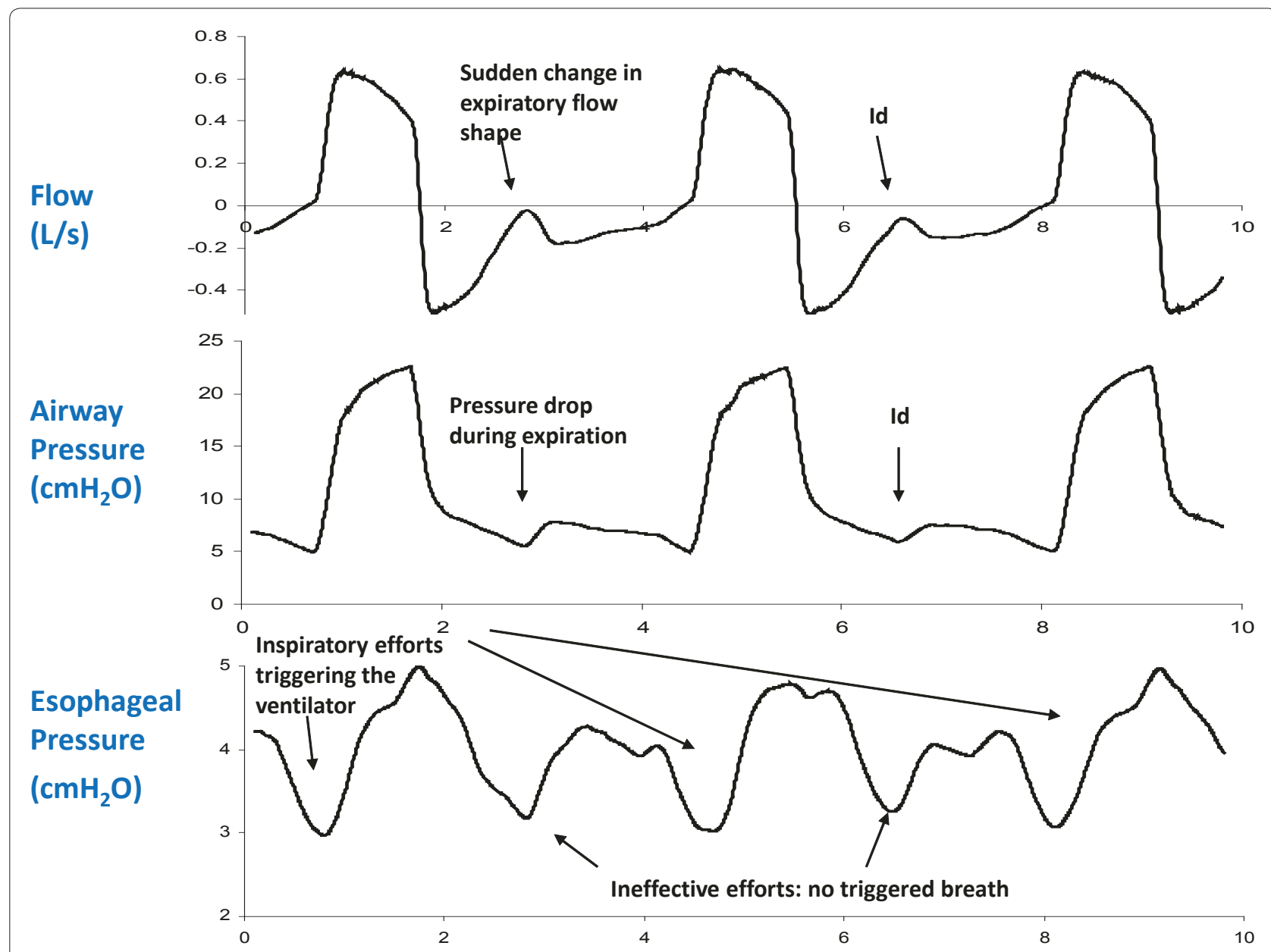

Figure 5. Example of ineffective efforts demonstrated on the esophageal pressure analysis. These missing efforts can be easily recognized on the airway pressure trace and the flow trace as indicated by the arrows. Id, idem.

are the true determinant of lung volume variations according to the equation:

$$
\Delta \mathrm{Vol}=\Delta \mathrm{P}_{\text {Ellung }} \times \mathrm{El}_{\text {lung' }}
$$

where $\mathrm{P}_{\mathrm{El}, \mathrm{lung}}$ is transpulmonary pressure and $\mathrm{El}_{l_{\text {lung }}}$ is the elastance of the lung.

In static conditions (that is, no flow), the pressure inside the lung can be easily estimated from $\mathrm{P}_{\text {aw }}$ (airway pressure), but the pressure outside the lung (that is, the pleural pressure, or $\mathrm{P}_{\mathrm{pl}}$ ) is not easily measurable and must be estimated from the esophageal pressure $\left(\mathrm{P}_{\text {es }}\right): \mathrm{P}_{\mathrm{Elllung}}=$ $\mathrm{P}_{\text {aw }}-\mathrm{P}_{\text {es. }}$.

For any change in lung volume, the higher the elastance of the chest wall $\left(\mathrm{El}_{\mathrm{cw}}\right)$, the greater the contribution of the $\mathrm{P}_{\mathrm{pl}}$ change to the total $\mathrm{P}_{\mathrm{aw}}$ change. The chest wall and the lung contribute to the change in airway pressure in proportion to their elastance:

$$
\begin{aligned}
& \Delta \mathrm{P}_{\text {aw }}=\Delta \mathrm{P}_{\text {Ellung }}+\Delta \mathrm{P}_{\text {es }}=\Delta \mathrm{Vol} \times \mathrm{El}_{\text {lung }}+\Delta \mathrm{Vol} \times \mathrm{El}_{\mathrm{cw}}= \\
& \Delta \mathrm{Vol} \times\left(\mathrm{El}_{\text {lung }}+\mathrm{El}_{\mathrm{cw}}\right)
\end{aligned}
$$

$\mathrm{P}_{\mathrm{El}}$ ing the real effector of lung volume changes and of potential ventilator-induced lung injury (VILI) and is of major importance in the setting of mechanical ventilation [68].

Measurement of $\mathrm{P}_{\mathrm{es}}$ is not always straightforward, in particular when absolute values are used [69], and some clinicians find $\mathrm{P}_{\mathrm{es}}$ difficult to use. Chiumello and colleagues [70] recently explored the concept of specific elastance, which reflects the intrinsic elastic properties of the lung parenchyma and which relates stress (transpulmonary pressure) and strain (change in volume relative to functional residual capacity (FRC)). Specific elastance is rather constant among patients with ARDS (and even healthy subjects) and thus the measurement of endexpiratory lung volume (EELV) could allow an effective evaluation of the $\mathrm{P}_{\mathrm{Ell} \text { lung }}$ change caused by $\mathrm{V}_{\mathrm{T}}$; that is, once the strain is measured, it is possible to infer the stress. The concept that the risk of VILI can be related to the ratio between $V_{T}$ and EELV has been suggested by positron emission tomography studies in patients with ARDS [71]. 


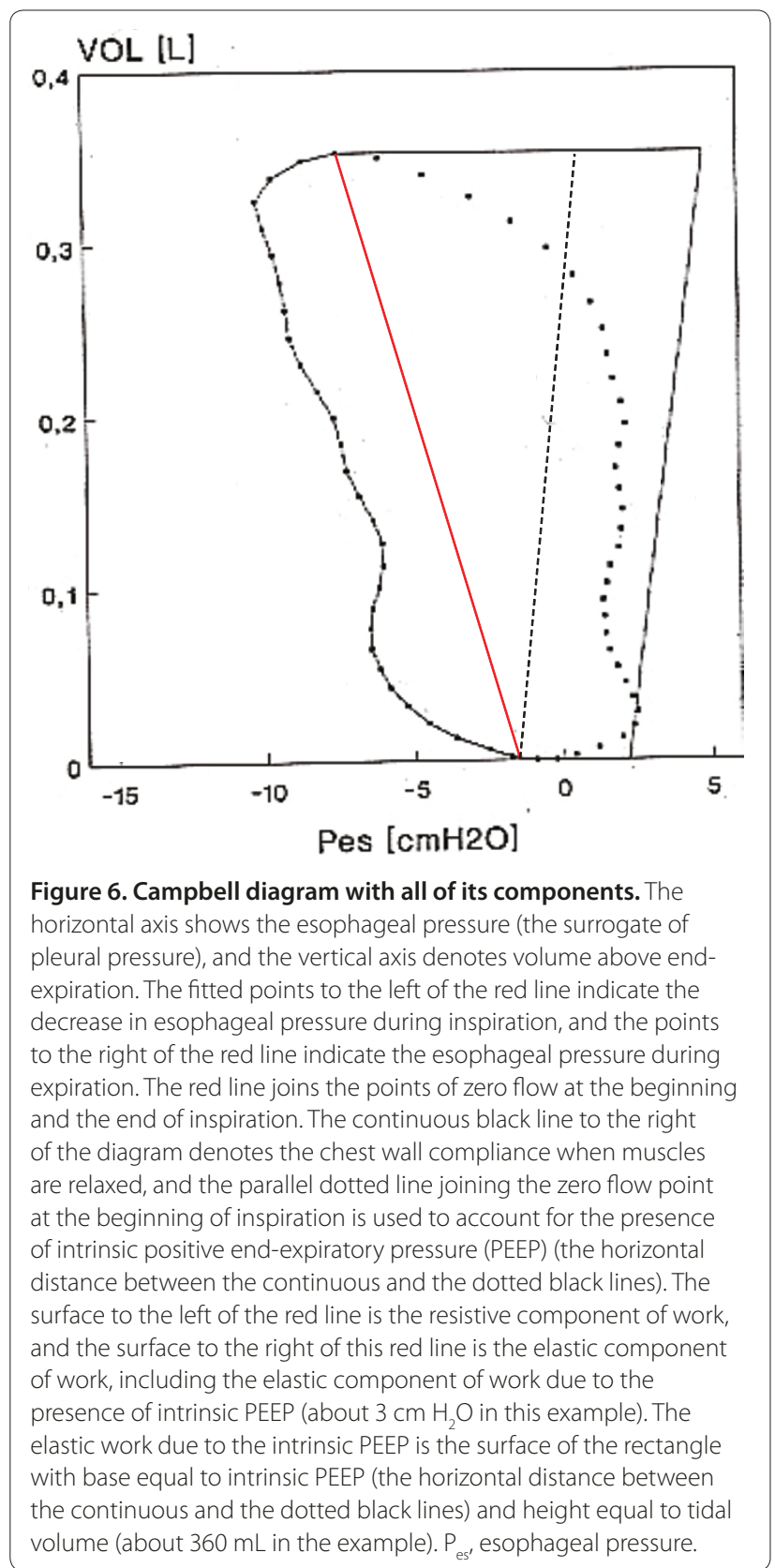

Specific problems arise from the fact that the ARDS lung is non-homogeneous, and some areas, possibly entire lobes, are not exposed to airway pressure because of collapse, whereas the boundary regions between ventilated and collapsed areas may be exposed to high distending pressures, potentially causing VILI. Attention should also be paid when applying these concepts to assisted rather than controlled breathing conditions [72]. The pressure developed by the inspiratory muscles and by the diaphragm may cause negative swings in pleural pressure, bringing the transpulmonary pressure to levels well beyond the VILI threshold. The effects of huge inspiratory efforts have only occasionally been investigated in patients with ARDS [73] but are known to cause lung edema in the experimental animal and in airwayobstructed patients. Decreased pleural pressure has been shown to be associated with cardiovascular failure during weaning [74], possibly because of increased transdiaphragmatic pressure and right heart overload [75].

In clinical practice, transpulmonary pressure estimate poses two problems. First, like WOB and the pressuretime product, it requires correct placement of an esophageal probe. The availability of nasogastric feeding tubes with esophageal balloons should greatly facilitate the use of these techniques. Second, ensuring the validity of the absolute value of esophageal pressure in a supine patient for estimating end-inspiratory or end-expiratory transpulmonary pressure values remains difficult.

\section{Abdominal pressure}

Increased intra-abdominal pressure (IAP) can decrease compliance of the lung and chest wall and increase dead space and shunt fraction $(\mathrm{Qs} / \mathrm{Qt})$. Increased IAP reduces the impact of transpulmonary pressure as the driving force for alveolar opening and prevention of closing. There is some relationship between abdominal and pleural pressures. IAP can be assessed fairly simply by using a bladder catheter [76], and given that high IAPs can have consequences in terms of diagnosis and management, more regular measurement of IAP is recommended.

\section{Lung volumes}

\section{Direct measurement of end-expiratory lung volume}

ARDS is associated with a marked reduction in lung volume [77]. Monitoring of FRC can provide information to assess pulmonary function. When the closed dilution technique is used, the patient breathes in a fixed concentration of helium or methane mixed with oxygen and the concentration in the expired breath can be used to calculate the FRC. This technique is used for research purposes. An alternative approach is a washout/washin technique using nitrogen or oxygen. Olegard and colleagues [78] reported that, by changing the $\mathrm{FiO}_{2}$ abruptly by as little as 0.1 , the FRC could be calculated by using standard gas-monitoring equipment. The precision of this method seems acceptable, and the method can be used even in the most severely hypoxemic patients $[79,80]$.

FRC is sex-, length-, and age-dependent. Ibanez and Raurich [81] showed that FRC decreased by $25 \%$ after changing the position from sitting to supine in healthy volunteers. Bikker and colleagues [82] found a reduction of $34 \%$ in mechanically ventilated patients with 'healthy' lungs and attributed this to the loss of muscle tension with sedation in ICU patients. In critically ill patients receiving mechanical ventilation and different levels of 
PEEP, it is better to speak of EELV [83]. Application of PEEP leads to increased EELV values as a result of recruitment or further distention of already ventilated alveoli. To differentiate between recruitment and distention, EELV changes can be combined with compliance values [82]. From the compliance calculation, one can determine the expected change in EELV for a given change in PEEP. If application of PEEP leads to a higher EELV, this method can be used to estimate alveolar recruitment at the bedside [84]. Measurement of EELV has been made available recently for routine use. Although we still have limited experience with this technique, it has considerable potential, at least in the management of patients with ARDS.

\section{Chest ultrasonography and computed tomography}

Chest ultrasonography can be useful at the bedside for early identification of edema as well as other abnormalities like pneumothorax or pleural effusion $[85,86]$. However, this technique requires training. Recently, it was shown that lung ultrasonography can be used to estimate alveolar reaeration in patients treated for ventilator-associated pneumonia [87] and to estimate PEEP-induced lung recruitment [88]. This is a relatively new but promising and non-invasive technique that could have important clinical applications in the ICU.

Computed tomography (CT) scanning can be useful to identify ongoing pathology. CT images can be used to compute average lung density and quantitate the respective amounts of air and tissue, but this approach is currently restricted to research $[42,89]$. CT could potentially have roles in guiding protective mechanical ventilation in ARDS and in appropriately setting $\mathrm{V}_{\mathrm{T}}$ and PEEP [90]. The major limitations are the need to transfer the patient to the CT scanner and the complex processing needed for analysis.

\section{Electrical bioimpedance tomography}

In electrical bioimpedance tomography (EIT), a current is applied via 16 electrodes positioned around the thorax. A scan of the impedance to flow in a slice of the thorax reflects changes in aeration but gives no information on EELV and measures only relative impedance without providing absolute values. Images can be subdivided into several regions and can be used to monitor regional ventilation. EIT can be used to show whether a recruitment maneuver has been successful and document the effects of positioning and of PEEP application [91,92].

The caudal thoracic level above the diaphragm is of particular importance because atelectasis due to mechanical ventilation can be expected at this level. Various studies have described ventilation distribution change maps to evaluate lung collapse or overdistension [93-95]. Costa and colleagues [93] introduced an algorithm for estimating recruitable alveolar collapse by using EIT. Bikker and colleagues [94] clearly visualized improvement or loss of ventilation in dependent and nondependent parts of the lung by using EIT measurements in ICU patients. When EIT was used at multiple levels in mechanically ventilated patients, ventilation distribution was shown to shift from the dorsal to ventral region but also from the caudal to cranial level during a decremental PEEP trial [95].

The increase in airway pressure during normal inspiration is followed by a continuous redistribution of gas from non-dependent to dependent regions. Thus, during the initial phase of inspiration, most of the inspiratory gas goes to the non-dependent lung, and during the last parts of inspiration, the most dependent parts receive the inspiratory flow, especially in patients with a positive response to a recruitment maneuver. This technique may thus represent a means of identifying responders and non-responders to recruitment during normal tidal ventilation, enabling one to avoid exposing non-responders to high-pressure recruitment maneuvers. Additional clinical work is now needed to delineate the place of EIT in the ICU as a qualitative tool to visualize ventilation distribution or as a quantitative technique to estimate the effects of interventions.

\section{Cardiopulmonary interactions Hemodynamic monitoring}

The use of hemodynamic monitoring in the unstable critically ill patient was reviewed recently [96]. Hemodynamic monitoring is particularly helpful during difficult weaning processes to separate cardiac from pulmonary aspects of failed weaning. The heart may not be able to meet the increased oxygen demand during weaning and then cardiac filling pressures generally increase and the mixed venous oxygen saturation $\left(\mathrm{SvO}_{2}\right)$ (or central venous oxygen saturation) decreases. $\mathrm{SvO}_{2}$ is a rather non-specific but sensitive kind of monitoring, as its changes reflect a change in one or more of the major homeostatic systems (respiration, circulation, and energy demand). During the weaning process, a reduction in $\mathrm{SvO}_{2}$ may be expected as spontaneous breathing represents a form of exercise, but a decrease in $\mathrm{SvO}_{2}$ may reflect the inability of the heart to face the increased oxygen demand, especially if arterial hypertension is present [97].

Echocardiographic evaluation may be helpful in acute respiratory failure, simply to identify a dilated right ventricle (RV) or RV failure, which may necessitate a decrease in PEEP or $\mathrm{V}_{\mathrm{T}}$ (or both) to reduce RV afterload. Measurement of pulmonary artery pressure can also be reliably obtained by Doppler measurements [98]. Echography can be particularly helpful just before a suspected difficult SBT and sometimes during the SBT. Patients at 
risk of weaning failure were identified as having decreased ejection fraction and increased filling pressures before SBT [99]. Echo can help to estimate pulmonary artery occlusion pressure elevation during SBT. The limitations of echocardiography are that it requires some training and is time-consuming, but it is an increasingly useful tool for cardiorespiratory monitoring in the ICU.

Cardiac biomarkers, like B-type natriuretic protein (BNP) or N-terminal prohormone of BNP (NT-proBNP), may be useful for diagnosing heart dysfunction but also for monitoring purposes, especially during weaning from mechanical ventilation $[100,101]$.

\section{Lung inflammation}

\section{Bronchoalveolar lavage studies}

Bronchoalveolar lavage (BAL) can be used to assess hemorrhage and measure neutrophils, eosinophils, hyaline membranes, lipid inclusion, and cancer cells (although this requires a careful cytologic examination of the alveolar fluid sampled). BAL fibrocyte levels are elevated in ARDS and related to outcome, and levels higher than $6 \%$ were observed in non-survivors [102]. BAL fluid analysis may also help to identify patients who may respond to steroids. Many studies have shown higher levels of inflammatory mediators (cytokines and so on) in BAL fluid of non-survivors than survivors of ARDS. Measuring cytokines or phosphorylation products may help to identify VILI, but there is a high signal-to-noise ratio at present. Among the limitations of BAL fluid analysis are that it needs an endoscope and requires some training, and there is no standardized technique (depends on the volume instilled and amount of fluid returned). A potential complication is hypoxemia. Detailed BAL analysis is suitable for bacteriological purposes, but detailed cytological or biomarker assessment is often reserved for clinical trials.

\section{Respiratory monitoring in specific situations Respiratory monitoring in acute respiratory distress syndrome}

As already mentioned, assessment of the severity of ARDS should include not only oxygenation but also dead space estimate and lung mechanics. Monitoring of plateau pressure, as a reflection of the maximal alveolar pressure, is essential. Potentially important tools for the most severe patients include esophageal pressure and lung volume measurements. P/V curves with assessment of recruitability could also be potentially useful. EVLW estimates may help in differential diagnosis.

\section{Respiratory monitoring in chronic obstructive pulmonary disease/asthma}

In the initial phase of mechanical ventilation, a detailed assessment of respiratory mechanics, including plateau pressure and auto-PEEP, is essential to characterize the patient. When patients are switched to triggered breaths, detection of asynchrony is very useful in titrating ventilator assistance.

\section{Respiratory monitoring in non-invasive ventilation}

Respiratory monitoring in patients receiving noninvasive ventilation (NIV) should start with a full clinical assessment: dyspnea, respiratory muscle function, comfort, mental alertness, and gastric distention are important signs. These clinical indicators should then be combined with additional objective variables for a full evaluation of respiratory status. Pulse oximetry is essential but does not provide information about $\mathrm{PCO}_{2}$. Expired $\mathrm{CO}_{2}$ can be measured (from the mask or helmet), but leaks often make these measurements unreliable. Transcutaneous capnometry offers a continuous and noninvasive method of monitoring alveolar ventilation [103]. Arterial blood gases remain important in assessing the response to therapy.

Patient-ventilator asynchrony occurs in almost one half of patients and may be related largely to leaks [104]. Clinical evaluation (tachypnea, accessory muscle activity, agitation, and lack of cooperation) or waveform analysis can be useful in assessing the presence of patientventilator dyssynchrony. Electromyography tracings are cumbersome, but airway pressures and flows can be used to monitor patient efforts and identify 'autotriggering, premature cycling, or ineffective triggering [105]. Inspired and expired $\mathrm{V}_{\mathrm{T}}$ values can help to identify air leaks.

In the hypoxemic patient, respiratory monitoring should also help to identify when to intubate the trachea (not too late!). Shock, including measurement of blood lactate levels, should also be looked for since the presence of acute circulatory failure is an exclusion criterion for NIV [106].

\section{Respiratory monitoring in the neurological patient}

Neurological dysfunction is one of the most frequent reasons for initiating mechanical ventilation [107]. Outcomes of critically ill neurological patients are driven mainly by the underlying neurological pathology $[108,109]$, and the influence of extracerebral organ dysfunction and ventilatory management on outcomes in this group of patients is not well established [110].

In mechanically ventilated neurological patients, no consensus has been reached about optimal $\mathrm{V}_{\mathrm{T}}$, PEEP, $\mathrm{PaO}_{2}$, or $\mathrm{PaCO}_{2}$ levels [111], largely because these patients have been universally excluded from randomized trials of lung-protective ventilation because of concerns about potential intracranial pressure (ICP) increases due to hypercapnia or increased thoracic pressures. Moreover, owing to persistently decreased levels of 
consciousness, typical weaning and liberation techniques used in medical-surgical ICU patients may not apply to this group [109,112]. Finally, tracheostomy is commonly implemented as part of the management of these neurological patients, but the technique of choice and timing are controversial [109].

Pulmonary hyperventilation rapidly reduces ICP by reducing cerebral blood flow (CBF). The effect on ICP is not sustained, whereas $\mathrm{CBF}$ may remain low, raising risks of ischemia $[113,114]$; hyperventilation should, therefore, be avoided during the first 24 hours after injury, when CBF is often already low [115]. The CBF level at which irreversible ischemia occurs has not been clearly established, but ischemic cell change has been demonstrated following traumatic brain injury and is likely to occur when CBF decreases to less than 15 to $20 \mathrm{~mL} / 100$ g per minute. Hyperventilation should, therefore, be used only for short-term management of raised ICP and only in patients with life-threatening intracranial hypertension $[115,116]$. If hyperventilation is used, jugular venous oxygen saturation $\left(\mathrm{SjO}_{2}\right)$ or brain tissue oxygen tension $\left(\mathrm{PbrO}_{2}\right)$ monitoring should be used to evaluate oxygen delivery where possible [115]. The ideal value for $\mathrm{PaCO}_{2}$ is one that keeps ICP to less than $20 \mathrm{~mm} \mathrm{Hg}$ and cerebral extraction of oxygen $\left(\mathrm{CEO}_{2}\right)$ to between $24 \%$ and $42 \%$ to avoid brain ischemia.

Moderate levels of PEEP (for example, less than $15 \mathrm{~cm} \mathrm{H}_{2} \mathrm{O}$ ) can be safely used in patients with cerebral lesions, mainly in those with low pulmonary compliance [117]. Hence, although care should be taken when applying PEEP in patients with neurological injury, it should not be withheld if needed to maintain adequate oxygenation [114].

Multimodal brain monitoring, including brain tissue oxygen tension, CBF measurement, and intracerebral microdialysis (with measurement of lactate, pyruvate, glutamate, glycerol, and inflammatory mediators), may be useful to optimize mechanical ventilation in patients with severe brain injury [118].

\section{Conclusions and perspectives}

Although most of the clinical interventions applied to the respiratory system of the critically ill are relatively simple, they are often misused, largely as a result of a poor understanding of the physiology underlying a specific intervention or of its consequences on the pathophysiology of respiratory disease or both. We need to encourage increased training in these techniques guided by a better knowledge of underlying mechanisms and appropriate use and correct interpretation of the data provided by available monitoring techniques.

Importantly, two key concepts can be highlighted:

1. Multiple variables need to be integrated: Many critically ill patients with respiratory failure have complex pathologies, and the respiratory failure is part of a broader multiple organ failure. Management will, therefore, require the consideration of monitored data from several different systems. This is one reason why it is difficult to develop protocols for the use of mechanical ventilation.

2. Monitoring of solitary static values provides limited information; evaluation of dynamic changes in variables over time is more important.

The future is likely to see advances in neuro-ventilatory coupling to limit the occurrence and adverse effects of patient-ventilator asynchrony. Biomarker panels will be developed to determine the risk of ARDS and VILI and to guide therapy. Chest ultrasonography and other, less invasive techniques will also be used more as they become more readily available at the bedside and training is improved.

\section{Abbreviations}

ARDS, acute respiratory distress syndrome; BAL, bronchoalveolar lavage; $\mathrm{BNP}$, B-type natriuretic protein; $\mathrm{CBF}$, cerebral blood flow; $\mathrm{CO}_{2^{\prime}}$ carbon dioxide; $\mathrm{COPD}$, chronic obstructive pulmonary disease; $\mathrm{CT}$, computed tomography; EELV, end-expiratory lung volume; EIT, electrical bioimpedance tomography; $\mathrm{El}_{\mathrm{cw}^{\prime}}$ elastance of the chest wall; $\mathrm{El}_{l_{\text {Iung }}}$ elastance of the lung; $\mathrm{ETT}$, endotracheal tube; EVLW, extravascular lung water; $\mathrm{FiO}_{2}$, inspired fraction of oxygen; $\mathrm{FRC}$, functional residual capacity; IAP, intra-abdominal pressure; ICP, intracranial pressure; ICU, intensive care unit; LIP, lower inflection point; NIV, non-invasive ventilation; $\mathrm{P}_{0.1}$ occlusion pressure; $\mathrm{PaCO}_{2^{\prime}}$ arterial partial pressure of carbon dioxide; $\mathrm{PaO}_{2}$, arterial partial pressure of oxygen; $\mathrm{P}$, airway pressure;

$\mathrm{PCO}_{2^{\prime}}$ partial pressure of carbon dioxide; $\mathrm{P}_{\mathrm{E}} \mathrm{CO}_{2^{\prime}}$ partial pressure of carbon dioxide in mixed expired gas; $P E E P$, positive end-expiratory pressure; $P$ transpulmonary pressure; $\mathrm{P}_{\text {es, }}$ esophageal pressure; $\mathrm{PetCO}_{2^{\prime}}$ end-tidal partial pressure of carbon dioxide; $P_{p^{\prime \prime}}$ pleural pressure; $\mathrm{PN}$, pressure/volume; $\mathrm{RV}$, right ventricle; $\mathrm{SBT}$, spontaneous breathing trial; $\mathrm{SVO}_{2}$, mixed venous oxygen saturation; UIP, upper inflection point; $\mathrm{Vd}_{\mathrm{alv^{ \prime }}}$ alveolar dead space; $\mathrm{Vd}_{\mathrm{aw} \mathrm{w}^{\prime}}$ airway dead space; $V_{d_{\text {phys }}}$ physiologic dead space; $V I L I$, ventilator-induced lung injury; $V_{T}$, tidal volume; WOB, work of breathing.

\section{Competing interests}

Over the last five years, L Brochard's laboratory has received research grants for specific research projects from the following companies: Dräger (SmartCare; Lübeck, Germany), Maquet (NAVA; Rastatt, Germany), Covidien (PAV+; Dublin, Ireland), General Electric Company (FRC; Fairfield, CT, USA), Fisher \& Paykel (Optiflow; Auckland, New Zealand), and Philips Respironics (NIV; Murrysville, PA, USA). GSM and FJB serve on the medical advisory board for Pulsion Medical Systems (Munich, Germany). L Blanch holds $€ 1,001$ to $€ 5,000$ in stock ownership in Better Care S.L., a spinoff of Corporació Sanitària Parc Taulí (Sabadell, Spain). JM has received research grants from Covidien and General Electric Company. J-CR has received research grants from Dräger, Covidien, and General Electric Company. DG is a member of the critical care medical advisory board of GE Healthcare (Madison, WI, USA) and has received speaking fees from Dräger and GE Healthcare. AV-B has received research grants from General Electric Company and Maquet. The research laboratory of SJ has received research grants from Dräger Medical France and Maquet France (Ardon, France). OS has received lecture fees and travel expenses from Dräger Medical and GE Healthcare and has received payment for a patent application from Dräger Medical. The other authors declare that they have no competing interests.

\section{Author details}

'Department of Intensive Care, Hôpitaux Universitaires de Genève, Rue Gabrielle-Perret-Gentil 4, 1211 Geneva, Switzerland; and Université de Genève, Switzerland. ${ }^{2}$ Division of Pulmonary, Allergy and Critical Care, Emory University School of Medicine, Grady Memorial Hospital, 615 Michael Street, Suite 205, Atlanta, GA 30322, USA. ${ }^{3}$ Critical Care Center, Corporacio Sanitaria Universitària Parc Tauli, Universitat Autònoma de Barcelona, 08208 Sabadell, 
Spain, CIBER Enfermedades Respiratorias, ISCiii, Madrid, Spain. ${ }^{4}$ Department of Surgical Sciences and Integrated Diagnostics, University of Genoa, San Martino Hospital, Largo Rosanna Benzi 8 16132, Genoa, Italy. ${ }^{5}$ Department of Anesthesia and Surgical Critical Care, Hospital Clínico Universitario, Avda Blasco Ibañez 17, 46010 Valencia, Spain. ${ }^{6}$ Division of Pulmonary and Critical Care Medicine, Edward Hines Jr. VA Hospital, 111N, 5th Avenue and Roosevelt Road, Hines, IL 60141, USA. ${ }^{7}$ Dipartimento di Anestesiologia, Terapia Intensive e Scienze Dermatologiche, and Dipartimento do Anestesia, Rianimazione (Intensive e Subintensiva) e Terapia del Dolore, Fondazione IRCCS Ca' Granda - Ospedale Maggiore Policlinico, Università degli Studi di Milano, via F, Sforza 35, 20122, Milan, Italy. ${ }^{8}$ Servicio Medicina Intensiva, Hospital de la Santa Creu i Sant Pau, Carrer St. Quintí 89, 08041 Barcelona, Spain. ${ }^{9}$ Department of Anesthesia and Intensive Care Medicine, University of Turin, S. Giovanni Battista, Molinette Hospital, Corso Dogliotti 14, 10126 Turin, Italy. ${ }^{10}$ Adult Intensive Care, Erasmus MC, Room H623,'s Gravendijkwal 230, 3015CE Rotterdam, The Netherlands. "'Intensive Care Unit, Section Thorax - Vascular disease - Abdomen - Metabolism, CHU Ambroise Paré, 9 avenue Charles-deGaulle, 92104 Boulogne, France. ${ }^{12}$ Anesthesia and Intensive Care, University of Milan-Bicocca, A.O. Ospedale S. Gerardo, Via Pergolesi 33, 20900 Monza, Italy. ${ }^{13}$ Department of Critical Care Medicine and Anesthesiology, Saint Eloi University Hospital and Montpellier School of Medicine, 80 Avenue Augustin Fliche, 34295 Montpellier - Cedex 5, France. ${ }^{14}$ Department of Anesthesiology and Intensive Care, Sahlgrenska University Hospital, Bla Straket 5, Gothenburg, SE 413 45, Sweden. ${ }^{15}$ Department of Intensive Care, Erasme Hospital, Université Libre de Bruxelles, 808 route de Lennik, 1070 Brussels, Belgium.

Published: 26 April 2012

\section{References}

1. Van de Louw A, Cracco C, Cerf C, Harf A, Duvaldestin P, Lemaire F, Brochard L: Accuracy of pulse oximetry in the intensive care unit. Intensive Care Med 2001, 27:1606-1613

2. Hinkelbein J, Genzwuerker HV, Sogl R, Fiedler F: Effect of nail polish on oxygen saturation determined by pulse oximetry in critically ill patients. Resuscitation 2007, 72:82-91.

3. Feiner JR, Severinghaus JW, Bickler PE: Dark skin decreases the accuracy of pulse oximeters at low oxygen saturation: the effects of oximeter probe type and gender. Anesth Analg 2007, 105:S18-23, tables.

4. Jensen LA, Onyskiw JE, Prasad NG: Meta-analysis of arterial oxygen saturation monitoring by pulse oximetry in adults. Heart Lung 1998, 27:387-408

5. Moller JT, Johannessen NW, Espersen K, Ravlo O, Pedersen BD, Jensen PF, Rasmussen NH, Rasmussen LS, Pedersen T, Cooper JB: Randomized evaluation of pulse oximetry in 20,802 patients: II. Perioperative events and postoperative complications. Anesthesiology 1993, 78:445-453.

6. Eberhard $\mathrm{P}$ : The design, use, and results of transcutaneous carbon dioxide analysis: current and future directions. Anesth Analg 2007, 105:S48-S52.

7. Romero PV, Lucangelo U, Lopez AJ, Fernandez R, Blanch L: Physiologically based indices of volumetric capnography in patients receiving mechanical ventilation. Eur Respir J 1997, 10:1309-1315

8. You B, Peslin R, Duvivier C, Vu VD, Grilliat JP: Expiratory capnography in asthma: evaluation of various shape indices. Eur Respir $J$ 1994, 7:318-323.

9. Lucangelo U, Bernabe F, Vatua S, Degrassi G, Villagra A, Fernandez R, Romero PV, Saura P, Borelli M, Blanch L: Prognostic value of different dead space indices in mechanically ventilated patients with acute lung injury and ARDS. Chest 2008, 133:62-71.

10. Raurich JM, Vilar M, Colomar A, Ibanez J, Ayestaran I, Perez-Barcena J, Llompart-Pou JA: Prognostic value of the pulmonary dead-space fraction during the early and intermediate phases of acute respiratory distress syndrome. Respir Care 2010, 55:282-287.

11. Lucangelo U, Blanch L: Dead space. Intensive Care Med 2004, 30:576-579.

12. Kuwabara S, Duncalf D: Effect of anatomic shunt on physiologic deadspace-to-tidal volume ratio--a new equation. Anesthesiology 1969, 31:575-577.

13. McSwain SD, Hamel DS, Smith PB, Gentile MA, Srinivasan S, Meliones JN, Cheifetz IM: End-tidal and arterial carbon dioxide measurements correlate across all levels of physiologic dead space. Respir Care 2010, 55:288-293.

14. Galia F, Brimioulle S, Bonnier F, Vandenbergen N, Dojat M, Vincent $J$, Brochard $\mathrm{L}$ : Use of maximum end-tidal $\mathrm{CO}(2)$ values to improve end-tidal CO(2) monitoring accuracy. Respir Care 2011, 56:278-283.

15. Kline JA, Israel EG, Michelson EA, O'Neil BJ, Plewa MC, Portelli DC: Diagnostic accuracy of a bedside D-dimer assay and alveolar dead-space measurement for rapid exclusion of pulmonary embolism: a multicenter study. JAMA 2001, 285:761-768.

16. Verschuren F, Heinonen E, Clause D, Roeseler J, Thys F, Meert P, Marion E, El Gariani A, Col J, Reynaert M, Liistro G: Volumetric capnography as a bedside monitoring of thrombolysis in major pulmonary embolism. Intensive Care Med 2004, 30:2129-2132.

17. Tusman G, Suarez-Sipmann F, Bohm SH, Pech T, Reissmann H, Meschino G, Scandurra A, Hedenstierna G: Monitoring dead space during recruitment and PEEP titration in an experimental model. Intensive Care Med 2006, 32:1863-1871.

18. Beydon L, Uttman L, Rawal R, Jonson B: Effects of positive end-expiratory pressure on dead space and its partitions in acute lung injury. Intensive Care Med 2002, 28:1239-1245.

19. Aboab J, Niklason L, Uttman L, Kouatchet A, Brochard L, Jonson B: CO2 elimination at varying inspiratory pause in acute lung injury. Clin Physio Funct Imaging 2007, 27:2-6.

20. Bernard GR, Artigas A, Brigham KL, Carlet J, Falke K, Hudson L, Lamy M, Legall $J R$, Morris A, Spragg R: The American-European Consensus Conference on ARDS. Definitions, mechanisms, relevant outcomes, and clinical trial coordination. Am J Respir Crit Care Med 1994, 149:818-824.

21. Aboab J, Louis B, Jonson B, Brochard L: Relation between PaO2/FIO2 ratio and FIO2: a mathematical description. Intensive Care Med 2006, 32:1494-1497.

22. Gowda MS, Klocke RA: Variability of indices of hypoxemia in adult respiratory distress syndrome. Crit Care Med 1997, 25:41-45.

23. Whiteley JP, Gavaghan DJ, Hahn CE: Variation of venous admixture, SF6 shunt, $\mathrm{PaO} 2$, and the $\mathrm{PaO} 2 / \mathrm{FIO} 2$ ratio with FIO2. Br J Anaesth 2002, 88:771-778.

24. Britos M, Smoot E, Liu KD, Thompson BT, Checkley W, Brower RG: The value of positive end-expiratory pressure and $\mathrm{FiO} 2$ criteria in the definition of the acute respiratory distress syndrome. Crit Care Med 2011, 39:2025-2030.

25. Di Marco F, Devaquet J, Lyazidi A, Galia F, da Costa NP, Fumagalli R, Brochard L: Positive end-expiratory pressure-induced functional recruitment in patients with acute respiratory distress syndrome. Crit Care Med 2010, 38:127-132.

26. Mekontso Dessap A, Boissier F, Leon R, Carreira S, Campo FR, Lemaire F, Brochard L: Prevalence and prognosis of shunting across patent foramen ovale during acute respiratory distress syndrome. Crit Care Med 2010, 38:1786-1792.

27. Willson DF, Thomas NJ, Markovitz BP, Bauman LA, DiCarlo JV, Pon S, Jacobs BR, Jefferson LS, Conaway MR, Egan EA: Effect of exogenous surfactant (calfactant) in pediatric acute lung injury: a randomized controlled trial. JAMA 2005, 293:470-476.

28. Nuckton TJ, Alonso JA, Kallet RH, Daniel BM, Pittet JF, Eisner MD, Matthay MA: Pulmonary dead-space fraction as a risk factor for death in the acute respiratory distress syndrome. N Engl J Med 2002, 346:1281-1286.

29. Gattinoni L, Bombino M, Pelosi P, Lissoni A, Pesenti A, Fumagalli R, Tagliabue $M$ : Lung structure and function in different stages of severe adult respiratory distress syndrome. JAMA 1994, 271:1772-1779.

30. Doyle RL, Szaflarski N, Modin GW, Wiener-Kronish JP, Matthay MA Identification of patients with acute lung injury. Predictors of mortality. Am J Respir Crit Care Med 1995, 152:1818-1824.

31. Monchi M, Bellenfant F, Cariou A, Joly LM, Thebert D, Laurent I, Dhainaut JF, Brunet F: Early predictive factors of survival in the acute respiratory distress syndrome. A multivariate analysis. Am J Respir Crit Care Med 1998, 158:1076-1081.

32. Sakka SG, Klein M, Reinhart K, Meier-Hellmann A: Prognostic value of extravascular lung water in critically ill patients. Chest 2002, 122:2080-2086

33. Lange NR, Schuster DP: The measurement of lung water. Crit Care 1999, 3:R19-R24

34. Brown LM, Liu KD, Matthay MA: Measurement of extravascular lung water using the single indicator method in patients: research and potential clinical value. Am J Physiol Lung Cell Mol Physiol 2009, 297:L547-L558.

35. Monnet X, Anguel N, Osman D, Hamzaoui O, Richard C, Teboul JL: Assessing pulmonary permeability by transpulmonary thermodilution allows differentiation of hydrostatic pulmonary edema from ALI/ARDS. Intensive Care Med 2007, 33:448-453.

36. Jonson B, Richard JC, Straus C, Mancebo J, Lemaire F, Brochard L: Pressurevolume curves and compliance in acute lung injury: evidence of recruitment above the lower inflection point. Am J Respir Crit Care Med 
1999, 159:1172-1178.

37. Richard JC, Brochard L, Vandelet P, Breton L, Maggiore SM, Jonson B, Clabault K, Leroy J, Bonmarchand G: Respective effects of end-expiratory and endinspiratory pressures on alveolar recruitment in acute lung injury. Crit Care Med 2003, 31:89-92.

38. Lu Q, Vieira SR, Richecoeur J, Puybasset L, Kalfon P, Coriat P, Rouby JJ: A simple automated method for measuring pressure-volume curves during mechanical ventilation. Am J Respir Crit Care Med 1999, 159:275-282.

39. Matamis D, Lemaire F, Harf A, Brun-Buisson C, Ansquer JC, Atlan G: Total respiratory pressure-volume curves in the adult respiratory distress syndrome. Chest 1984, 86:58-66.

40. Roupie E, Dambrosio M, Servillo G, Mentec H, el Atrous S, Beydon L, BrunBuisson C, Lemaire F, Brochard L: Titration of tidal volume and induced hypercapnia in acute respiratory distress syndrome. Am J Respir Crit Care Med 1995, 152:121-128.

41. Crotti S, Mascheroni D, Caironi P, Pelosi P, Ronzoni G, Mondino M, Marini JJ, Gattinoni L: Recruitment and derecruitment during acute respiratory failure: a clinical study. Am J Respir Crit Care Med 2001, 164:131-140.

42. Pelosi P, Goldner M, McKibben A, Adams A, Eccher G, Caironi P, Losappio S, Gattinoni L, Marini JJ: Recruitment and derecruitment during acute respiratory failure: an experimental study. Am J Respir Crit Care Med 2001, 164:122-130.

43. Owens RL, Hess DR, Malhotra A, Venegas JG, Harris RS: Effect of the chest wall on pressure-volume curve analysis of acute respiratory distress syndrome lungs. Crit Care Med 2008, 36:2980-2985

44. Demory D, Arnal JM, Wysocki M, Donati S, Granier I, Corno G, Durand-Gasselin $\mathrm{J}$ : Recruitability of the lung estimated by the pressure volume curve hysteresis in ARDS patients. Intensive Care Med 2008, 34:2019-2025.

45. Maggiore SM, Jonson B, Richard JC, Jaber S, Lemaire F, Brochard L: Alveolar derecruitment at decremental positive end-expiratory pressure levels in acute lung injury: comparison with the lower inflection point, oxygenation, and compliance. Am J Respir Crit Care Med 2001, 164:795-801.

46. Grasso S, Terragni P, Mascia L, Fanelli V, Quintel M, Herrmann P, Hedenstierna G, Slutsky AS, Ranieri VM: Airway pressure-time curve profile (stress index) detects tidal recruitment/hyperinflation in experimental acute lung injury. Crit Care Med 2004, 32:1018-1027.

47. Grasso S, Stripoli T, De Michele M, Bruno F, Moschetta M, Angelelli G, Munno I, Ruggiero V, Anaclerio R, Cafarelli A, Driessen B, Fiore T: ARDSnet ventilatory protocol and alveolar hyperinflation: role of positive end-expiratory pressure. Am J Respir Crit Care Med 2007, 176:761-767.

48. Formenti P, Graf J, Santos A, Gard KE, Faltesek K, Adams AB, Dries DJ, Marini JJ: Non-pulmonary factors strongly influence the stress index. Intensive Care Med 2011, 37:594-600

49. Jaber S, Jung B, Matecki S, Petrof BJ: Clinical review: Ventilator-induced diaphragmatic dysfunction - human studies confirm animal model findings! Crit Care 2011, 15:206.

50. Jaber S, Petrof BJ, Jung B, Chanques G, Berthet JP, Rabuel C, Bouyabrine H, Courouble P, Koechlin-Ramonatxo C, Sebbane M, Similowski T, Scheuermann V, Mebazaa A, Capdevila X, Mornet D, Mercier J, Lacampagne A, Philips A, Matecki S: Rapidly progressive diaphragmatic weakness and injury during mechanical ventilation in humans. Am J Respir Crit Care Med 2011, 183:364-371.

51. Polkey ML, Duguet A, Luo Y, Hughes PD, Hart N, Hamnegard CH, Green M, Similowski T, Moxham J: Anterior magnetic phrenic nerve stimulation: laboratory and clinical evaluation. Intensive Care Med 2000, 26:1065-1075.

52. Sinderby C: Neurally adjusted ventilatory assist (NAVA). Minerva Anestesiol 2002, 68:378-380

53. Georgopoulos D, Prinianakis G, Kondili E: Bedside waveforms interpretation as a tool to identify patient-ventilator asynchronies. Intensive Care Med 2006, 32:34-47.

54. Leung P, Jubran A, Tobin MJ: Comparison of assisted ventilator modes on triggering, patient effort, and dyspnea. Am J Respir Crit Care Med 1997, 155:1940-1948

55. Thille AW, Cabello B, Galia F, Lyazidi A, Brochard L: Reduction of patientventilator asynchrony by reducing tidal volume during pressure-support ventilation. Intensive Care Med 2008, 34:1477-1486.

56. Thille AW, Rodriguez P, Cabello B, Lellouche F, Brochard L: Patient-ventilator asynchrony during assisted mechanical ventilation. Intensive Care Med 2006, 32:1515-1522.

57. Parthasarathy $\mathrm{S}$, Tobin MJ: Effect of ventilator mode on sleep quality in critically ill patients. Am J Respir Crit Care Med 2002, 166:1423-1429.
58. Tassaux D, Gainnier M, Battisti A, Jolliet P: Impact of expiratory trigger setting on delayed cycling and inspiratory muscle workload. Am J Respir Crit Care Med 2005, 172:1283-1289.

59. Cabello B, Mancebo J: Work of breathing. Intensive Care Med 2006, 32:1311-1314

60. Mancebo J, Albaladejo P, Touchard D, Bak E, Subirana M, Lemaire F, Harf A, Brochard L: Airway occlusion pressure to titrate positive end-expiratory pressure in patients with dynamic hyperinflation. Anesthesiology 2000, 93:81-90.

61. Vassilakopoulos T: Understanding wasted/ineffective efforts in mechanically ventilated COPD patients using the Campbell diagram. Intensive Care Med 2008, 34:1336-1339.

62. Jubran A, Grant BJ, Laghi F, Parthasarathy S, Tobin MJ: Weaning prediction esophageal pressure monitoring complements readiness testing. Am J Respir Crit Care Med 2005, 171:1252-1259.

63. Mancebo J, Amaro P, Lorino H, Lemaire F, Harf A, Brochard L: Effects of albuterol inhalation on the work of breathing during weaning from mechanical ventilation. Am Rev Respir Dis 1991, 144:95-100.

64. Alberti A, Gallo F, Fongaro A, Valenti S, Rossi A: P0.1 is a useful parameter in setting the level of pressure support ventilation. Intensive Care Med 1995, 21:547-553.

65. Field S, Sanci S, Grassino A: Respiratory muscle oxygen consumption estimated by the diaphragm pressure-time index. J App/ Physiol 1984, 57:44-51.

66. Nava S, Bruschi C, Fracchia C, Braschi A, Rubini F: Patient-ventilator interaction and inspiratory effort during pressure support ventilation in patients with different pathologies. Eur Respir J 1997, 10:177-183.

67. Sassoon CS, Light RW, Lodia R, Sieck GC, Mahutte CK: Pressure-time product during continuous positive airway pressure, pressure support ventilation, and T-piece during weaning from mechanical ventilation. Am Rev Respir Dis 1991, 143:469-475.

68. Talmor D, Sarge T, Malhotra A, O'Donnell CR, Ritz R, Lisbon A, Novack V, Loring $\mathrm{SH}$ : Mechanical ventilation guided by esophageal pressure in acute lung injury. N Engl J Med 2008, 359:2095-2104.

69. Vieillard-Baron A, Jardin F: Esophageal pressure in acute lung injury. N Engl J Med 2009, 360:832.

70. Chiumello D, Carlesso E, Cadringher P, Caironi P, Valenza F, Polli F, Tallarini F, Cozzi P, Cressoni M, Colombo A, Marini JJ, Gattinoni L: Lung stress and strain during mechanical ventilation for acute respiratory distress syndrome. Am J Respir Crit Care Med 2008, 178:346-355.

71. Bellani G, Guerra L, Musch G, Zanella A, Patroniti N, Mauri T, Messa C, Pesenti A: Lung regional metabolic activity and gas volume changes induced by tidal ventilation in patients with acute lung injury. Am J Respir Crit Care Med 2011, 183:1193-1199.

72. Marini JJ: Spontaneously regulated versus controlled ventilation of acute lung injury/acute respiratory distress syndrome. Curr Opin Crit Care 2011, $17 \cdot 24-29$

73. Kallet RH, Alonso JA, Luce JM, Matthay MA: Exacerbation of acute pulmonary edema during assistaed mechanical ventilation using a low tidal volume, lung protective strategy. Chest 1999, 116:1826-1832.

74. Lemaire F, Teboul JL, Cinotti L, Giotto G, Abrouk F, Steg G, Macquin-Mavier I, Zapol WM: Acute left ventricular dysfunction during unsuccessful weaning from mechanical ventilation. Anesthesiology 1988, 69:171-179.

75. Permutt S: Circulatory effects of weaning from mechanical ventilation: the importance of transdiaphragmatic pressure. Anesthesiology 1988, 69:157-160.

76. Malbrain ML, Chiumello D, Pelosi P, Wilmer A, Brienza N, Malcangi V, Bihari D, Innes R, Cohen J, Singer P, Japiassu A, Kurtop E, De Keulenaer BL, Daelemans R, Del Turco M, Cosimini P, Ranieri M, Jacquet L, Laterre PF, Gattinoni L: Prevalence of intra-abdominal hypertension in critically ill patients: a multicentre epidemiological study. Intensive Care Med 2004, 30:822-829.

77. Falke KJ, Pontoppidan H, Kumar A, Leith DE, Geffin B, Laver MB: Ventilation with end-expiratory pressure in acute lung disease. J Clin Invest 1972, 51:2315-2323.

78. Olegard C, Sondergaard S, Houltz E, Lundin S, Stenqvist O: Estimation of functional residual capacity at the bedside using standard monitoring equipment: a modified nitrogen washout/washin technique requiring a small change of the inspired oxygen fraction. Anesth Analg 2005, 101:206-212

79. Chiumello D, Cressoni M, Chierichetti M, Tallarini F, Botticelli M, Berto V, Mietto C, Gattinoni L: Nitrogen washout/washin, helium dilution and computed 
tomography in the assessment of end expiratory lung volume. Crit Care 2008, 12:R150.

80. Patroniti N, Saini M, Zanella A, Weismann D, Isgro S, Bellani G, Foti G, Pesenti $A$ : Measurement of end-expiratory lung volume by oxygen washinwashout in controlled and assisted mechanically ventilated patients. Intensive Care Med 2008, 34:2235-2240.

81. Ibanez J, Raurich JM: Normal values of functional residual capacity in the sitting and supine positions. Intensive Care Med 1982, 8:173-177.

82. Bikker IG, van Bommel J, Reis Miranda D, Bakker J, Gommers D: Endexpiratory lung volume during mechanical ventilation: a comparison with reference values and the effect of positive end-expiratory pressure in intensive care unit patients with different lung conditions. Crit Care 2008, 12:R145.

83. Reis Miranda D, Gommers D: Precise use of medical terminology. Crit Care Med 2006, 34:1854-1855.

84. Dellamonica J, Lerolle N, Sargentini C, Beduneau G, Di Marco F, Mercat A, Richard JC, Diehl JL, Mancebo J, Rouby JJ, Lu Q, Bernardin G, Brochard L: PEEP-induced changes in lung volume in acute respiratory distress syndrome. Two methods to estimate alveolar recruitment. Intensive Care Med 2011, 37:1595-1604.

85. Remerand F, Dellamonica J, Mao Z, Ferrari F, Bouhemad B, Jianxin Y, Arbelot C, Lu Q, Ichai C, Rouby JJ: Multiplane ultrasound approach to quantify pleural effusion at the bedside. Intensive Care Med 2010, 36:656-664.

86. Reissig A, Copetti R, Kroegel C: Current role of emergency ultrasound of the chest. Crit Care Med 2011, 39:839-845.

87. Bouhemad B, Liu ZH, Arbelot C, Zhang M, Ferarri F, Le Guen M, Girard M, Lu Q, Rouby JJ: Ultrasound assessment of antibiotic-induced pulmonary reaeration in ventilator-associated pneumonia. Crit Care Med 2010, 38:84-92.

88. Bouhemad B, Brisson H, Le-Guen M, Arbelot C, Lu Q, Rouby JJ: Bedside ultrasound assessment of positive end-expiratory pressure-induced lung recruitment. Am J Respir Crit Care Med 2011, 183:341-347.

89. Puybasset L, Cluzel P, Chao N, Slutsky AS, Coriat P, Rouby JJ: A computed tomography scan assessment of regional lung volume in acute lung injury. The CT Scan ARDS Study Group. Am J Respir Crit Care Med 1998, 158:1644-1655.

90. Pelosi P, Rocco PR, de Abreu MG: Use of computed tomography scanning to guide lung recruitment and adjust positive-end expiratory pressure. Curr Opin Crit Care 2011, 17:268-274.

91. Lindgren S, Odenstedt H, Olegard C, Sondergaard S, Lundin S, Stenqvist O: Regional lung derecruitment after endotracheal suction during volumeor pressure-controlled ventilation: a study using electric impedance tomography. Intensive Care Med 2007, 33:172-180.

92. Fagerberg A, Stenqvist O, Aneman A: Electrical impedance tomography applied to assess matching of pulmonary ventilation and perfusion in a porcine experimental model. Crit Care 2009, 13:R34.

93. Costa EL, Borges JB, Melo A, Suarez-Sipmann F, Toufen C Jr., Bohm SH, Amato MB: Bedside estimation of recruitable alveolar collapse and hyperdistension by electrical impedance tomography. Intensive Care Med 2009, 35:1132-1137.

94. Bikker IG, Leonhardt S, Reis MD, Bakker J, Gommers D: Bedside measurement of changes in lung impedance to monitor alveolar ventilation in dependent and non-dependent parts by electrical impedance tomography during a positive end-expiratory pressure trial in mechanically ventilated intensive care unit patients. Crit Care 2010, 14:R100.

95. Bikker IG, Preis C, Egal M, Bakker J, Gommers D: Electrical impedance tomography measured at two thoracic levels can visualize the ventilation distribution changes at the bedside during a decremental positive endexpiratory pressure (PEEP) trial. Crit Care 2011, 15:R193.

96. Vincent JL, Rhodes A, Perel A, Martin CS, Rocca GD, Vallet B, Pinsky MR, Hofer CK, Teboul JL, de Boode WP, Walley KR, Maggiorini M, Singer M: Update on hemodynamic monitoring: a consensus of 16. Crit Care 2011, 15:229.

97. Jubran A, Mathru M, Dries D, Tobin MJ: Continuous recordings of mixed venous oxygen saturation during weaning from mechanical ventilation and the ramifications thereof. Am J Respir Crit Care Med 1998, 158:1763-1769.

98. Bouhemad B, Ferrari F, Leleu K, Arbelot C, Lu Q, Rouby JJ: Echocardiographic Doppler estimation of pulmonary artery pressure in critically ill patients with severe hypoxemia. Anesthesiology 2008, 108:55-62.

99. Caille V, Amiel JB, Charron C, Belliard G, Vieillard-Baron A, Vignon P: Echocardiography: a help in the weaning process. Crit Care 2010, 14:R120.
100. Mekontso-Dessap A, de Prost N, Girou E, Braconnier F, Lemaire F, BrunBuisson C, Brochard L: B-type natriuretic peptide and weaning from mechanical ventilation. Intensive Care Med 2006, 32:1529-1536.

101. Grasso S, Leone A, De Michele M, Anaclerio R, Cafarelli A, Ancona G, Stripoli T, Bruno F, Pugliese P, Dambrosio M, Dalfino L, Di Serio F, Fiore T: Use of $\mathrm{N}$-terminal pro-brain natriuretic peptide to detect acute cardiac dysfunction during weaning failure in difficult-to-wean patients with chronic obstructive pulmonary disease. Crit Care Med 2007, 35:96-105.

102. Quesnel C, Piednoir P, Gelly J, Nardelli L, Lecon V, Lasocki S, Bouadma L, Philip I, Elbim C, Mentre F, Crestani B, Dehoux M: Alveolar fibrocyte percentage is an independent predictor of poor outcome in patients with acute lung injury. Crit Care Med 2012, 40:21-28.

103. Storre JH, Steurer B, Kabitz HJ, Dreher M, Windisch W: Transcutaneous PCO2 monitoring during initiation of noninvasive ventilation. Chest 2007, 132:1810-1816.

104. Vignaux L, Vargas F, Roeseler J, Tassaux D, Thille AW, Kossowsky MP, Brochard $L$, Jolliet $P$ : Patient-ventilator asynchrony during non-invasive ventilation for acute respiratory failure: a multicenter study. Intensive Care Med 2009, 35:840-846.

105. Unroe M, Maclntyre N: Evolving approaches to assessing and monitoring patient-ventilator interactions. Curr Opin Crit Care 2010, 16:261-268.

106. Antonelli M, Conti G, Moro ML, Esquinas A, Gonzalez-Diaz G, Confalonieri M, Pelaia P, Principi T, Gregoretti C, Beltrame F, Pennisi MA, Arcangeli A, Proietti R, Passariello M, Meduri GU: Predictors of failure of noninvasive positive pressure ventilation in patients with acute hypoxemic respiratory failure: a multi-center study. Intensive Care Med 2001, 27:1718-1728.

107. Pelosi P, Ferguson ND, Frutos-Vivar F, Anzueto A, Putensen C, Raymondos K, Apezteguia C, Desmery P, Hurtado J, Abroug F, Elizalde J, Tomicic V, Cakar N, Gonzalez M, Arabi Y, Moreno R, Esteban A: Management and outcome of mechanically ventilated neurologic patients. Crit Care Med 2011 39:1482-1492.

108. Minardi J, Crocco TJ: Management of traumatic brain injury: first link in chain of survival. Mt Sinai J Med 2009, 76:138-144.

109. Esteban A, Anzueto A, Frutos F, Alia I, Brochard L, Stewart TE, Benito S, Epstein SK, Apezteguia C, Nightingale P, Arroliga AC, Tobin MJ: Characteristics and outcomes in adult patients receiving mechanical ventilation: a 28-day international study. JAMA 2002, 287:345-355.

110. Zygun DA, Kortbeek JB, Fick GH, Laupland KB, Doig CJ: Non-neurologic organ dysfunction in severe traumatic brain injury. Crit Care Med 2005 33:654-660.

111. Lowe GJ, Ferguson ND: Lung-protective ventilation in neurosurgical patients. Curr Opin Crit Care 2006, 12:3-7.

112. Namen AM, Ely EW, Tatter SB, Case LD, Lucia MA, Smith A, Landry S, Wilson JA, Glazier SS, Branch CL, Kelly DL, Bowton DL, Haponik EF: Predictors of successful extubation in neurosurgical patients. Am J Respir Crit Care Med 2001, 163:658-664.

113. Steiner LA, Balestreri M, Johnston AJ, Czosnyka M, Coles JP, Chatfield DA, Smielewski P, Pickard JD, Menon DK: Sustained moderate reductions in arterial $\mathrm{CO} 2$ after brain trauma time-course of cerebral blood flow velocity and intracranial pressure. Intensive Care Med 2004, 30:2180-2187.

114. Deem S: Management of acute brain injury and associated respiratory issues. Respir Care 2006, 51:357-367.

115. Bratton SL, Chestnut RM, Ghajar J, McConnell Hammond FF, Harris OA, Hartl R, Manley GT, Nemecek A, Newell DW, Rosenthal G, Schouten J, Shutter L, Timmons SD, Ullman JS, Videtta W, Wilberger JE, Wright DW: Guidelines for the management of severe traumatic brain injury. XIV. Hyperventilation. J Neurotrauma 2007, 24 Suppl 1:S87-S90.

116. Stocchetti $\mathrm{N}$, Maas Al, Chieregato A, van der Plas AA: Hyperventilation in head injury: a review. Chest 2005, 127:1812-1827

117. Caricato A, Conti G, Della CF, Mancino A, Santilli F, Sandroni C, Proietti R, Antonelli M: Effects of PEEP on the intracranial system of patients with head injury and subarachnoid hemorrhage: the role of respiratory system compliance. J Trauma 2005, 58:571-576.

118. Young N, Rhodes JK, Mascia L, Andrews PJ: Ventilatory strategies for patients with acute brain injury. Curr Opin Crit Care 2010, 16:45-52.

doi:10.1186/cc11146

Cite this article as: Brochard L, et al:: Clinical review: Respiratory monitoring

in the ICU - a consensus of 16. Critical Care 2012, 16:219. 